\title{
Imidazole-Imidazole Hydrogen Bonding in the pH-Sensing Histidine Side Chains of Influenza A M2
}

\author{
Kumar Tekwani Movellan, Melanie Wegstroth, Kerstin Overkamp, Andrei Leonov, Stefan Becker, \\ and Loren B. Andreas*
}

Cite This: J. Am. Chem. Soc. 2020, 142, 2704-2708

Read Online

ACCESS | Llll Metrics \& More | 国 Article Recommendations | sl Supporting Information

ABSTRACT: The arrangement of histidine side chains in influenza A M2 tetramer determines their $\mathrm{p} K_{\mathrm{a}}$ values, which define $\mathrm{pH}$ controlled proton conduction critical to the virus lifecycle. Both water-associated and hydrogen-bonded imidazole-imidazolium histidine quaternary structures have been proposed, based on crystal structures and NMR chemical shifts, respectively. Here we show, using the conduction domain construct of $\mathrm{M} 2$ in lipid bilayers, that the imidazole rings are hydrogen bonded even at a $\mathrm{pH}$ of 7.8 in the neutral charge state. An intermolecular $8.9 \pm 0.3 \mathrm{~Hz}^{2 \mathrm{~h}} \mathrm{~J}_{\mathrm{NN}}$ hydrogen bond is observed between $\mathrm{H} 37 \mathrm{~N}_{\varepsilon}$ and $\mathrm{N}_{\delta}$ recorded in a fully protonated sample with $100 \mathrm{kHz}$ magic-angle spinning. This interaction could not be detected in the drug-bound sample.

$\mathrm{T}$ he M2 protein from influenza $A$ assembles as a tetramer $^{1-3}$ and is tuned to conduct protons across the virus envelope upon external acidification during endocytosis, which leads to membrane fusion and release of RNA into the host organism. ${ }^{3,4}$ This process is controlled by the quaternary structure of the tetramer and the protonation state of the four $\mathrm{pH}$-sensitive $\mathrm{H} 37$ residues. Reported $\mathrm{p} K_{\mathrm{a}}$ values for $\mathrm{H} 37$ range from 6.3 to 8.2 , for the first two protonation events, with a consensus that lies above the value of 6 found for the histidine side chain in aqueous solution. ${ }^{5-8}$ Correlating these $\mathrm{p} K_{\mathrm{a}}$ measurements with the endosomal $\mathrm{pH}$ resulted in the understanding that the third proton to enter the channel results in conduction. ${ }^{7}$ Yet despite many reports of the M2 structure from oriented sample NMR, ${ }^{9-11}$ solution NMR, ${ }^{12-14}$ magic-angle spinning $\mathrm{NMR},{ }^{15-17}$ and crystallography, ${ }^{18-21}$ there is still no consensus in the literature regarding the structural configuration at $\mathrm{H} 37$ that leads to these shifted $\mathrm{p} K_{\mathrm{a}}$ values.

Based on ${ }^{15} \mathrm{~N}$ chemical shifts, Cross and co-workers proposed that the doubly charged tetramer arranges its histidine side chains to form imidazole-imidazolium dimers, delocalizing the positive charge and explaining the high $\mathrm{p} K_{\mathrm{a}}$. This imidazole arrangement is not seen in crystal structures, ${ }^{18-21}$ at either high or low $\mathrm{pH}$. Instead, changes in $\mathrm{pH}$ are associated with opening or closing of the C-terminal side of the tetramer, rather than changes in the geometry of the histidine side chain. In a recent high-resolution X-ray free electron laser (XFEL) crystal structure, the histidine is found hydrogen bonded to water with $\mathrm{H} 37$ residues separated $\sim 7 \AA$ apart. $^{21}$

In further support of the hydrogen-bonded dimer arrangement, Cross and co-workers measured proton shifts up to 18.5 ppm for a full-length $\mathrm{M} 2$ sample at $\mathrm{pH} 6.2$, where the +2 charge state (half imidazole, half imidazolium) is expected to be the dominant form. ${ }^{8}$ This supports the presence of a strong imidazole-imidazolium hydrogen bond, since strong bonding and a low barrier are associated with proton chemical shifts above 16 ppm. ${ }^{22-24}$ In contrast, Hong et al. measured proton shifts between 8 and $15 \mathrm{ppm}$ in the transmembrane (TM) construct (residues 22-46), consistent with normal hydrogen bonds. ${ }^{25}$ Whether M2 is ideally reconstituted with the oleoylbased lipids of the former, similar diphytanoyl lipids, or "virus mimetic" preparations of the latter remains debated.,

While the XFEL and NMR data strongly support that H37 in the TM construct forms hydrogen bonds to water, so far only indirect evidence in the form of chemical shifts exists in support of the dimer configuration. The $18.5 \mathrm{ppm}$ proton shift observed in M2 is significantly higher than the $16.8 \mathrm{ppm}$ shift of $\mathrm{H}_{\delta 1}$ in a N-H---O hydrogen bond in histidine crystals ${ }^{27}$ and was recorded for full-length M2 in lipid bilayers, a close match to physiological conditions. Yet considering the conflicting XFEL and NMR data in the TM construct, a direct measurement is needed to prove that a hydrogen-bonded histidine dimer is one of the stable arrangements of the tetramer.

Measurement of J-couplings in NMR is an established method to identify hydrogen-bonding interactions. For example, detection of amide nitrogen to carbonyl J-coupling $\left({ }^{3 h} J_{\mathrm{NC}}\right)$ establishes hydrogen bonding in proteins in solution. ${ }^{28,29}$ An unusual example of a histidine-histidine $\mathrm{N}-\mathrm{H}---\mathrm{N} J$-coupling $\left({ }^{2 \mathrm{~h}} \mathrm{~J}_{\mathrm{NN}}\right)$ of the type proposed in $\mathrm{M} 2$ occurs for apomyoglobin. ${ }^{30}$ A coupling strength of $10 \mathrm{~Hz}$ was reported for the $\mathrm{N}-\mathrm{N}$ distance of $2.75 \AA$ in the holomyoglobin crystal structure (PDB 1MBD), which is shorter than in base pairs $(\sim 2.9 \AA)$. It was noted that although within measurement errors, this fits with the understanding that closer distances result in stronger couplings. Further examples of $\mathrm{N}-\mathrm{H}---\mathrm{N}$

Received: October 11, 2019

Published: January 23, 2020 
hydrogen bonds occur in DNA and RNA, where coupling strengths of $6-7 \mathrm{~Hz}$ were observed in solution. ${ }^{31,32}$ In the solid state, ${ }^{2 \mathrm{~h}} J_{\mathrm{NN}}$ couplings of $\sim 7$ to $8 \mathrm{~Hz}$ were reported for crystalline small molecules, ${ }^{33,34}$ and the values for base-pairing interactions are consistent with solution measurements. ${ }^{35,36}$ The smaller ${ }^{3 \mathrm{~h}} J_{\mathrm{NC}}$ couplings can be detected in protein microcrystals, ${ }^{37}$ and van der Waals interactions result in even weaker couplings. ${ }^{38}$ The coupling strength can now be reliably computed and is a sensitive indicator of the molecular geometry. ${ }^{39,40}$

We measured $\mathrm{M} 2_{18-60}$ in 1,2-diphytanoyl-sn-glycero-3phosphatidylcholine bilayers at $\mathrm{pH} 7.8$, as in previous work. ${ }^{26}$ We used the 18-60 "conductance domain" construct since it recapitulates the proton conduction rates and drug sensitivity properties of the full-length protein in liposome flux assays. ${ }^{12}$ In this construct, a $C_{2}$ symmetric dimer of dimers arrangement $^{26}$ at high $\mathrm{pH}$ results in two $\mathrm{H} 37 \mathrm{H}_{\varepsilon 2}$ chemical shifts, at 12 and $14.5 \mathrm{ppm},{ }^{5}$ herein indexed as " $\mathrm{A}$ " and " $\mathrm{B}$ ", respectively. Peak doubling also occurs in full-length $\mathrm{M} 2$. $^{41}$ The question remains whether the 4-fold symmetry is broken by hydrogen-bonded dimers or whether only water is the hydrogen-bonding partner. Although the $\mathrm{H} 37$ proton chemical shifts are indicative of normal hydrogen bonds, a dimer arrangement in the neutral charge state would be expected to persist in the +2 state, since the dimer further stabilizes a positive charge, according to $a b$ initio quantum chemical calculations on imidazole dimers ${ }^{42}$ and in the core of the M2 tetramer. ${ }^{43}$ Such calculations show that a positive charge strengthens the dimer interaction and might lead to a low barrier hydrogen bond.

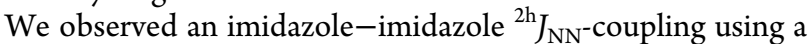
homonuclear $\mathrm{INEPT}^{44}$ period on the nitrogen channel, combined with cross-polarization (CP) for detection of the attached proton (Figure 1). When a homonuclear J-coupling is present, an additional peak occurs at the ${ }^{15} \mathrm{~N}$ frequency of the coupled spin, with a buildup of intensity following the wellknown relation $\sin ^{2}(2 \pi J t) \exp \left(-\tau / T_{2}\right)$. Since the original peak follows $\cos ^{2}(2 \pi J t) \exp \left(-\tau / T_{2}\right)$, normalization by the total signal results in a single parameter fit to $\sin ^{2}(2 \pi J t)$. We measured a $\mathrm{N}_{\delta 1}-\mathrm{N}_{\varepsilon 2} J$-coupling of $8.9 \pm 0.3 \mathrm{~Hz}$ (Figure 2), which was unambiguously assigned to an intermolecular interaction (Figure 3). This intermolecular $\mathrm{N}-\mathrm{H}---\mathrm{N}{ }^{2 \mathrm{~h}} J_{\mathrm{NN}}$ coupling occurs for the most strongly downfield shifted proton at $14.5 \mathrm{ppm}$. No homonuclear J-coupling could be detected for the other $\mathrm{N}_{\varepsilon 2}$, indicating that its attached $\mathrm{H}_{\varepsilon 2}$ at $12.1 \mathrm{ppm}$ is likely hydrogen bonded to oxygen.

Since only nitrogen hydrogen-bonding partners are detected in the above J-couplings, we sought indirect evidence of additional hydrogen-bonding partners through long nitrogen to proton $\mathrm{CP}$ of $6 \mathrm{~ms}$ (Figure 3, blue). Similar to measurements in $\mathrm{TM} \mathrm{M} 2,{ }^{25}$ we detected contact to water, here specifically for $\mathrm{N}_{\delta 1}$ of $\mathrm{H} 37_{\mathrm{B}}$. This nitrogen is not involved in the $\mathrm{N}-\mathrm{H}---\mathrm{N}$ hydrogen bond. The chemical shift of the water proton is found at $4.85 \mathrm{ppm}$, the same shift correlated with the $\mathrm{R}$ and $\mathrm{K}$ side chains of the amphipathic helix (see Figure S2) and separate from bulk water at $4.75 \mathrm{ppm}$, similar to associated water in other membrane proteins. ${ }^{45}$ This indicates that the channel water near $\mathrm{N}_{\delta 1}$ of $\mathrm{H} 37_{\mathrm{B}}$ exchanges during the $6 \mathrm{~ms} \mathrm{CP}$.

In order to assign the tautomeric states of histidine, we recorded a CP-based out-and-back $(\mathrm{H})(\mathrm{C}) \mathrm{N}(\mathrm{C}) \mathrm{H}$ spectrum. The use of one-bond transfer times ensures that the $\delta 2$ proton is connected with only the $\varepsilon 2$ nitrogen. Correlations are found
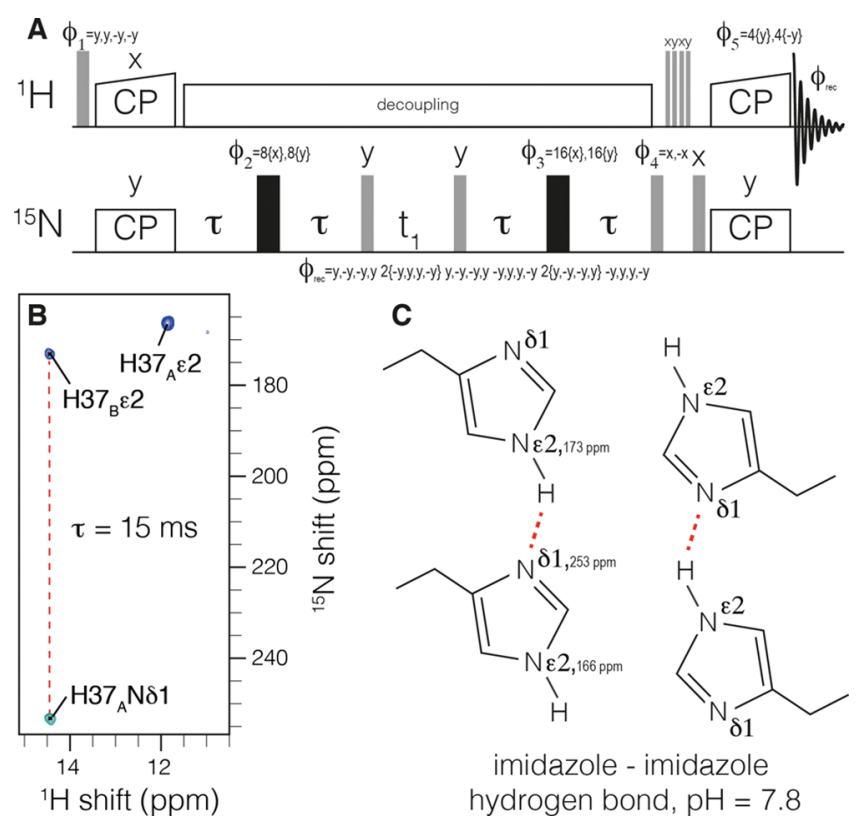

C

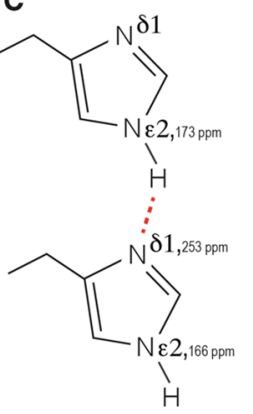

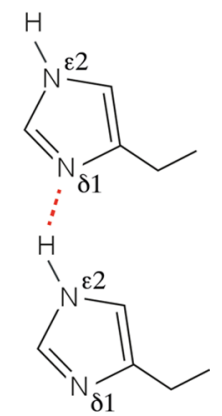

imidazole - imidazole

hydrogen bond, $\mathrm{pH}=7.8$

Figure 1. Measurement of ${ }^{2 \mathrm{~h}} J_{\mathrm{NHN}}$ hydrogen bonding in $\mathrm{H} 37$ imidazole dimers within influenza M2. The pulse sequence is shown in (a). Cross-polarization (CP) is used to establish ${ }^{15} \mathrm{~N}$ polarization. A homonuclear out-and-back INEPT period follows to record the chemical shift of the J-coupled nitrogen. Following water suppression, CP returns signal to protons for detection. The spectrum in (b) was recorded with a $\tau$ of $15 \mathrm{~ms}$ and clearly shows a negative peak indicative of an intermolecular $J$-coupling and a $C_{2}$ symmetric tetramer at $\mathrm{H} 37$, as shown schematically in (c).

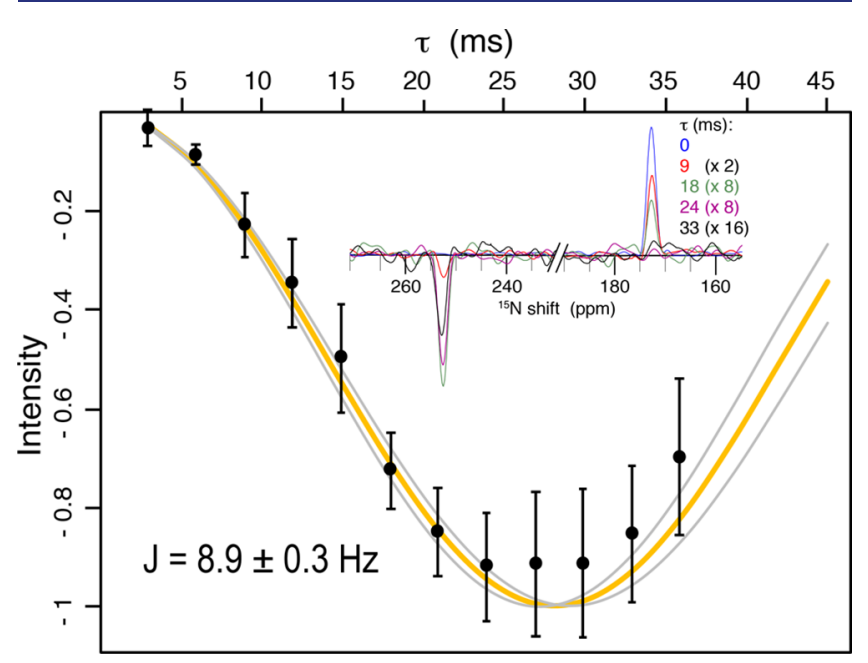

Figure 2. Quantification of the intermolecular ${ }^{2 \mathrm{~h}} J_{\mathrm{NHN}} J$-coupling. In the inset, slices of the $2 \mathrm{D}$ spectrum at the proton frequency of 14.5 are shown for the indicated mixing times. The experimental data (points) are shown with $2 \sigma$ error bars accounting for random spectral noise. Relaxation was accounted for by dividing each intensity at 254 ppm by the total signal magnitude of the slice. The best fit (orange) resulted in a coupling strength of $8.9 \pm 0.3 \mathrm{~Hz}$. The curves in gray indicate the error at twice the standard deviation, $\sigma$, as estimated with a Monte Carlo approach and considering random spectral noise. The first point was acquired with 8 scans $(1.5 \mathrm{~h})$, while the last point required 128 scans $(26 \mathrm{~h})$ due to transverse relaxation (see Figure S1).

at 165 and $172 \mathrm{ppm}$, corresponding to the two protonated imidazole nitrogen resonances observed in the $\mathrm{N}-\mathrm{H}$ spectrum and establishes de novo that both signals are from $\tau$ tautomers. 

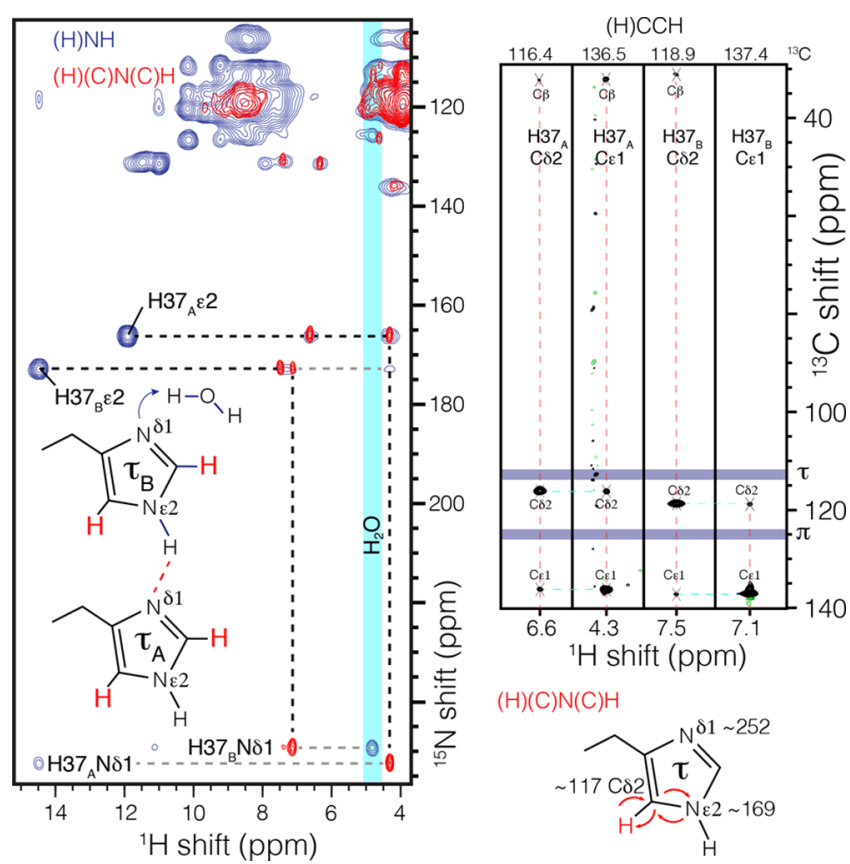

Figure 3. Histidine-water contact and assignment of the H37 tautomer state. In blue, an $\mathrm{NH}$ correlation spectrum shows magnetization transfer from a nonprotonated imidazole nitrogen at $\sim 250 \mathrm{ppm}$ to water $(4.85 \mathrm{ppm})$ using $6 \mathrm{~ms}$ of CP. In red, the nitrogen and carbon resonances are assigned by out-and-back one-bond $\mathrm{CP}$ transfer $(\mathrm{H})(\mathrm{C}) \mathrm{N}(\mathrm{C}) \mathrm{H}$. The $\mathrm{H}_{\delta 2}$ is correlated only with $\mathrm{N} \varepsilon 2$ in this magnetization transfer scheme, which resonates at $\sim 170 \mathrm{ppm}$ and establishes that all histidine residues in the channel are in the $\tau$ tautomer. Magnetization transfers are indicated by curved arrows. The $\delta$ and $\varepsilon$ carbon assignments were confirmed in an $\mathrm{RFDR}^{46}$-based (H) $\mathrm{CCH}$ spectrum (black).

The $\mathrm{C}_{\delta 2}$ resonance of $\mathrm{H} 37_{\mathrm{B}}$ is found midway between the shifts observed in crystals of $\tau$ and $\pi$ tautomers of histidine (Figure 3, purple), ${ }^{27}$ highlighting the need to independently establish the tautomeric states.

That both water-associated and hydrogen-bonded dimer conformations of $\mathrm{H} 37$ exist under different conditions suggests that these conformations are both relatively stable. The main differences in sample preparation that result in these different structures are the nature of the membrane mimetic and the length of the construct. The fact that the ${ }^{2 \mathrm{~h}} J_{\mathrm{NN}}$ coupling is observed in the functional "conductance domain" construct in lipid bilayers suggests that it is a relevant state and that the proton affinities of the dimer control the interconversion to a conducting channel. This does not rule out the possibility that other quaternary structures may also lead to a proton current in virus particles, although a different $\mathrm{p} K_{\mathrm{a}}$ would be expected at $\mathrm{H} 37$. This is in line with the large range of $\mathrm{p} K_{\mathrm{a}}$ values reported for $\mathrm{M} 2$. $^{5-8}$

Interestingly, with the inhibitor rimantadine bound to the pore, the exchangeable histidine protons shift upfield by about $3 \mathrm{ppm}$, and no ${ }^{2 \mathrm{~h}} J_{\mathrm{NN}}$ coupling could be detected (Figure 4). This disruption of the hydrogen-bonding interaction explains the difference in $\mathrm{H} 37 \mathrm{pK}$ in the drug-bound state ${ }^{47}$ and lends support to the hypothesis that imidazole dimers are functionally important. The simplest explanation for inhibitor efficacy is pore blockage preventing passage of hydronium ion. Yet significant chemical shift perturbations were detected widely over transmembrane residues. ${ }^{26,48}$ This suggested that the inhibitors have far-reaching effects, modifying the conforma-

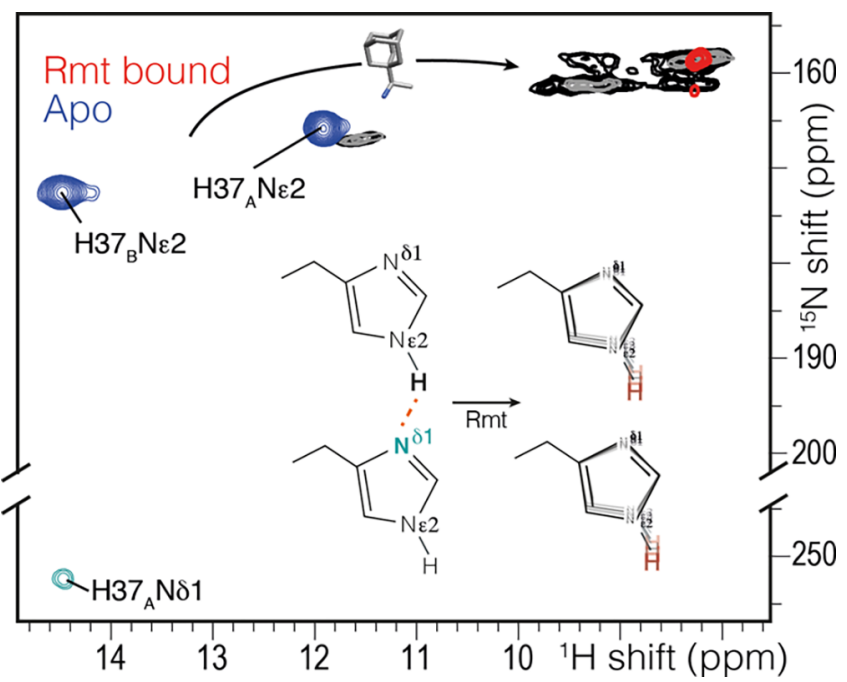

Figure 4. Chemical shift changes in the histidine side chain upon addition of the drug rimantadine (Rmt) using the pulse sequence of Figure 1 with a $\tau$ of $6 \mathrm{~ms}$ (blue, red) and (H)NH spectra with $25 \mathrm{~ms}$ (gray) or $200 \mathrm{~ms}$ (black) of ${ }^{15} \mathrm{~N}$ exchange during the water suppression. A 3-5 ppm change is observed in the drug-bound spectrum (red), and no ${ }^{2 \mathrm{~h}} J_{\mathrm{NHN}} J$-coupling was observed. Instead, the imidazole $\mathrm{NH}$ peaks are broadened, and the peaks at $9 \mathrm{ppm}$ are in exchange. The $(\mathrm{H}) \mathrm{NH}$ spectra were acquired at $250 \mathrm{~K}$ and $80 \mathrm{kHz}$ MAS to reduce the temperature by $\sim 10{ }^{\circ} \mathrm{C}$ to slow exchange.

tional distribution of the protein. However, it has been difficult to connect a specific structural change to the chemical shift perturbations. It is now clear that in the conductance domain construct, rimantadine affects the structure of the channel by impacting the hydrogen bonding of the important functional residue $\mathrm{H} 37$.

In conclusion, through the measurement of a ${ }^{2 h} J_{N N}$ coupling, we confirmed the existence of imidazole-imidazole dimers in the M2 protein from influenza. Such a configuration was proposed to stabilize positive charge in the tetrameric channel. However, direct evidence of the interaction was not previously reported, and crystal structures of M2 showed an alternate structure, leading to controversy over whether the dimeric histidine arrangement exists at all in M2. We have solved this controversy through NMR measurements of M2 in lipid bilayers at high $\mathrm{pH}$, where we observe a neutral charge state at the functional $\mathrm{H} 37$ residue. The coupling strength is consistent with a normal hydrogen-bonding interaction. Binding of the drug rimantadine resulted in breaking of this hydrogen bond. It remains to be seen whether evidence can be found that this geometry persists in the important +2 charge state, where imidazole-imidazolium dimers have been proposed, and whether such a state results in a normal hydrogen bond or a low barrier hydrogen bond.

\section{ASSOCIATED CONTENT}

\section{St Supporting Information}

The Supporting Information is available free of charge at https://pubs.acs.org/doi/10.1021/jacs.9b10984.

Sample preparation and acquisition parameters, raw signal amplitudes of Figure 2, full $(\mathrm{H}) \mathrm{NH}$ spectrum (PDF) 


\section{AUTHOR INFORMATION}

\section{Corresponding Author}

Loren B. Andreas - Department of NMR Based Structural Biology, Max Planck Institute for Biophysical Chemistry, Göttingen 37077, Germany; (1) orcid.org/0000-0003-32169065; Email: land@nmr.mpibpc.mpg.de

\section{Authors}

Kumar Tekwani Movellan - Department of NMR Based Structural Biology, Max Planck Institute for Biophysical Chemistry, Göttingen 37077, Germany

Melanie Wegstroth - Department of NMR Based Structural Biology, Max Planck Institute for Biophysical Chemistry, Göttingen 37077, Germany

Kerstin Overkamp - Department of NMR Based Structural Biology, Max Planck Institute for Biophysical Chemistry, Göttingen 37077, Germany

Andrei Leonov - Department of NMR Based Structural Biology, Max Planck Institute for Biophysical Chemistry, Göttingen 37077, Germany

Stefan Becker - Department of NMR Based Structural Biology, Max Planck Institute for Biophysical Chemistry, Göttingen 37077, Germany

Complete contact information is available at:

https://pubs.acs.org/10.1021/jacs.9b10984

\section{Notes}

The authors declare no competing financial interest.

\section{ACKNOWLEDGMENTS}

We thank James Chou for providing the expression plasmid. We acknowledge financial support from the Max Planck Society and the DFG Emmy Noether program (grant AN 1316/1-1).

\section{REFERENCES}

(1) Kochendoerfer, G. G.; Salom, D.; Lear, J. D.; Wilk-Orescan, R.; Kent, S. B.; DeGrado, W. F. Total chemical synthesis of the integral membrane protein influenza A virus M2: role of its C-terminal domain in tetramer assembly. Biochemistry 1999, 38 (37), 11905-13.

(2) Sakaguchi, T.; Tu, Q.; Pinto, L. H.; Lamb, R. A. The active oligomeric state of the minimalistic influenza virus M2 ion channel is a tetramer. Proc. Natl. Acad. Sci. U. S. A. 1997, 94 (10), 5000-5.

(3) Sugrue, R. J.; Hay, A. J. Structural characteristics of the M2 protein of influenza A viruses: evidence that it forms a tetrameric channel. Virology 1991, 180 (2), 617-24.

(4) Sugrue, R. J.; Bahadur, G.; Zambon, M. C.; Hall-Smith, M.; Douglas, A. R.; Hay, A. J. Specific structural alteration of the influenza haemagglutinin by amantadine. EMBO J. 1990, 9 (11), 3469-76.

(5) Colvin, M. T.; Andreas, L. B.; Chou, J. J.; Griffin, R. G. Proton association constants of His 37 in the Influenza-A M218-60 dimerof-dimers. Biochemistry 2014, 53 (38), 5987-94.

(6) Hu, F.; Schmidt-Rohr, K.; Hong, M. NMR detection of $\mathrm{pH}$ dependent histidine-water proton exchange reveals the conduction mechanism of a transmembrane proton channel. J. Am. Chem. Soc. 2012, 134 (8), 3703-13.

(7) Hu, J.; Fu, R.; Nishimura, K.; Zhang, L.; Zhou, H. X.; Busath, D. D.; Vijayvergiya, V.; Cross, T. A. Histidines, heart of the hydrogen ion channel from influenza A virus: toward an understanding of conductance and proton selectivity. Proc. Natl. Acad. Sci. U. S. A. 2006, 103 (18), 6865-70.

(8) Miao, Y.; Fu, R.; Zhou, H. X.; Cross, T. A. Dynamic Short Hydrogen Bonds in Histidine Tetrad of Full-Length M2 Proton Channel Reveal Tetrameric Structural Heterogeneity and Functional Mechanism. Structure 2015, 23 (12), 2300-2308.
(9) Hu, J.; Asbury, T.; Achuthan, S.; Li, C.; Bertram, R.; Quine, J. R.; $\mathrm{Fu}, \mathrm{R}$; Cross, T. A. Backbone structure of the amantadine-blocked trans-membrane domain $\mathrm{M} 2$ proton channel from Influenza A virus. Biophys. J. 2007, 92 (12), 4335-43.

(10) Sharma, M.; Yi, M.; Dong, H.; Qin, H.; Peterson, E.; Busath, D. D.; Zhou, H. X.; Cross, T. A. Insight into the mechanism of the influenza A proton channel from a structure in a lipid bilayer. Science 2010, 330 (6003), 509-12.

(11) Wang, J.; Kim, S.; Kovacs, F.; Cross, T. A. Structure of the transmembrane region of the M2 protein $\mathrm{H}(+)$ channel. Protein Sci. 2001, 10 (11), 2241-50.

(12) Pielak, R. M.; Schnell, J. R.; Chou, J. J. Mechanism of drug inhibition and drug resistance of influenza A M2 channel. Proc. Natl. Acad. Sci. U. S. A. 2009, 106 (18), 7379-84.

(13) Schnell, J. R.; Chou, J. J. Structure and mechanism of the M2 proton channel of influenza A virus. Nature 2008, 451 (7178), 591-5.

(14) Pielak, R. M.; Chou, J. J. Solution NMR structure of the V27A drug resistant mutant of influenza A M2 channel. Biochem. Biophys. Res. Commun. 2010, 401 (1), 58-63.

(15) Andreas, L. B.; Reese, M.; Eddy, M. T.; Gelev, V.; Ni, Q. Z.; Miller, E. A.; Emsley, L.; Pintacuda, G.; Chou, J. J.; Griffin, R. G. Structure and Mechanism of the Influenza A M218-60 Dimer of Dimers. J. Am. Chem. Soc. 2015, 137 (47), 14877-86.

(16) Cady, S. D.; Mishanina, T. V.; Hong, M. Structure of amantadine-bound $\mathrm{M} 2$ transmembrane peptide of influenza A in lipid bilayers from magic-angle-spinning solid-state NMR: the role of Ser31 in amantadine binding. J. Mol. Biol. 2009, 385 (4), 1127-41.

(17) Cady, S. D.; Schmidt-Rohr, K.; Wang, J.; Soto, C. S.; Degrado, W. F.; Hong, M. Structure of the amantadine binding site of influenza M2 proton channels in lipid bilayers. Nature 2010, 463 (7281), 68992.

(18) Stouffer, A. L.; Acharya, R.; Salom, D.; Levine, A. S.; Di Costanzo, L.; Soto, C. S.; Tereshko, V.; Nanda, V.; Stayrook, S.; DeGrado, W. F. Structural basis for the function and inhibition of an influenza virus proton channel. Nature 2008, 451 (7178), 596-9.

(19) Acharya, R.; Carnevale, V.; Fiorin, G.; Levine, B. G.; Polishchuk, A. L.; Balannik, V.; Samish, I.; Lamb, R. A.; Pinto, L. H.; DeGrado, W. F.; Klein, M. L. Structure and mechanism of proton transport through the transmembrane tetrameric M2 protein bundle of the influenza A virus. Proc. Natl. Acad. Sci. U. S. A. 2010, 107 (34), $15075-80$.

(20) Thomaston, J. L.; Wu, Y.; Polizzi, N.; Liu, L.; Wang, J.; DeGrado, W. F. X-ray Crystal Structure of the Influenza A M2 Proton Channel S31N Mutant in Two Conformational States: An Open and Shut Case. J. Am. Chem. Soc. 2019, 141 (29), 11481-11488.

(21) Thomaston, J. L.; Woldeyes, R. A.; Nakane, T.; Yamashita, A.; Tanaka, T.; Koiwai, K.; Brewster, A. S.; Barad, B. A.; Chen, Y.; Lemmin, T.; Uervirojnangkoorn, M.; Arima, T.; Kobayashi, J.; Masuda, T.; Suzuki, M.; Sugahara, M.; Sauter, N. K.; Tanaka, R.; Nureki, O.; Tono, K.; Joti, Y.; Nango, E.; Iwata, S.; Yumoto, F.; Fraser, J. S.; DeGrado, W. F. XFEL structures of the influenza M2 proton channel: Room temperature water networks and insights into proton conduction. Proc. Natl. Acad. Sci. U. S. A. 2017, 114 (51), 13357-13362.

(22) Brown, S. P. Applications of high-resolution H-1 solid-state NMR. Solid State Nucl. Magn. Reson. 2012, 41, 1-27.

(23) Lorente, P.; Shenderovich, I. G.; Golubev, N. S.; Denisov, G. S.; Buntkowsky, G.; Limbach, H. H. H-1/N-15 NMR chemical shielding, dipolar N-15, H-2 coupling and hydrogen bond geometry correlations in a novel series of hydrogen-bonded acid-base complexes of collidine with carboxylic acids. Magn. Reson. Chem. 2001, 39, S18-S29.

(24) Sharif, S.; Fogle, E.; Toney, M. D.; Denisov, G. S.; Shenderovich, I. G.; Buntkowsky, G.; Tolstoy, P. M.; Huot, M. C.; Limbach, H. H. NMR localization of protons in critical enzyme hydrogen bonds. J. Am. Chem. Soc. 2007, 129 (31), 9558.

(25) Hong, M.; Fritzsching, K. J.; Williams, J. K. Hydrogen-bonding partner of the proton-conducting histidine in the influenza M2 proton channel revealed from $1 \mathrm{H}$ chemical shifts. J. Am. Chem. Soc. 2012, 134 (36), 14753-5. 
(26) Andreas, L. B.; Eddy, M. T.; Pielak, R. M.; Chou, J.; Griffin, R. G. Magic angle spinning NMR investigation of influenza A M2(1860): support for an allosteric mechanism of inhibition. J. Am. Chem. Soc. 2010, 132 (32), 10958-60.

(27) Li, S.; Hong, M. Protonation, tautomerization, and rotameric structure of histidine: a comprehensive study by magic-angle-spinning solid-state NMR. J. Am. Chem. Soc. 2011, 133 (5), 1534-44.

(28) Cordier, F.; Grzesiek, S. Direct observation of hydrogen bonds in proteins by interresidue (3h) J(NC') scalar couplings. J. Am. Chem. Soc. 1999, 121 (7), 1601-1602.

(29) Cornilescu, G.; Hu, J. S.; Bax, A. Identification of the hydrogen bonding network in a protein by scalar couplings. J. Am. Chem. Soc. 1999, 121 (12), 2949-2950.

(30) Hennig, M.; Geierstanger, B. H. Direct detection of a histidinehistidine side chain hydrogen bond important for folding of apomyoglobin. J. Am. Chem. Soc. 1999, 121 (22), 5123-5126.

(31) Dingley, A. J.; Grzesiek, S. Direct observation of hydrogen bonds in nucleic acid base pairs by internucleotide (2)J(NN) couplings. J. Am. Chem. Soc. 1998, 120 (33), 8293-8297.

(32) Pervushin, K.; Ono, A.; Fernandez, C.; Szyperski, T.; Kainosho, M.; Wuthrich, K. NMR scalar couplings across Watson-Crick base pair hydrogen bonds in DNA observed by transverse relaxationoptimized spectroscopy. Proc. Natl. Acad. Sci. U. S. A. 1998, 95 (24), $14147-51$.

(33) Brown, S. P.; Perez-Torralba, M.; Sanz, D.; Claramunt, R. M.; Emsley, L. Determining hydrogen-bond strengths in the solid state by NMR: the quantitative measurement of homonuclear J couplings. Chem. Commun. (Cambridge, U. K.) 2002, No. 17, 1852-3.

(34) Brown, S. P.; Perez-Torralba, M.; Sanz, D.; Claramunt, R. M.; Emsley, L. The direct detection of a hydrogen bond in the solid state by NMR through the observation of a hydrogen-bond mediated (15)N [bond] (15)N J coupling. J. Am. Chem. Soc. 2002, 124 (7), 1152-3.

(35) Pham, T. N.; Masiero, S.; Gottarelli, G.; Brown, S. P. Identification by $15 \mathrm{~N}$ refocused INADEQUATE MAS NMR of intermolecular hydrogen bonding that directs the self-assembly of modified DNA bases. J. Am. Chem. Soc. 2005, 127 (46), 16018-9.

(36) Pham, T. N.; Griffin, J. M.; Masiero, S.; Lena, S.; Gottarelli, G.; Hodgkinson, P.; Filip, C.; Brown, S. P. Quantifying hydrogen-bonding strength: the measurement of $2 \mathrm{hJNN}$ couplings in self-assembled guanosines by solid-state $15 \mathrm{~N}$ spin-echo MAS NMR. Phys. Chem. Chem. Phys. 2007, 9 (26), 3416-23.

(37) Schanda, P.; Huber, M.; Verel, R.; Ernst, M.; Meier, B. H. Direct detection of $(3 \mathrm{~h}) \mathrm{J}\left(\mathrm{NC}^{\prime}\right)$ hydrogen-bond scalar couplings in proteins by solid-state NMR spectroscopy. Angew. Chem., Int. Ed. 2009, 48 (49), 9322-5.

(38) Li, J.; Wang, Y.; An, L.; Chen, J.; Yao, L. Direct Observation of $\mathrm{CH} / \mathrm{CH}$ van der Waals Interactions in Proteins by NMR. J. Am. Chem. Soc. 2018, 140 (9), 3194-3197.

(39) Joyce, S. A.; Yates, J. R.; Pickard, C. J.; Brown, S. P. Density functional theory calculations of hydrogen-bond-mediated NMR J coupling in the solid state. J. Am. Chem. Soc. 2008, 130 (38), 1266370.

(40) Hughes, C. E.; Reddy, G. N. M.; Masiero, S.; Brown, S. P.; Williams, P. A.; Harris, K. D. M. Determination of a complex crystal structure in the absence of single crystals: analysis of powder X-ray diffraction data, guided by solid-state NMR and periodic DFT calculations, reveals a new 2'-deoxyguanosine structural motif. Chem. Sci. 2017, 8 (5), 3971-3979.

(41) Can, T. V.; Sharma, M.; Hung, I.; Gor'kov, P. L.; Brey, W. W.; Cross, T. A. Magic angle spinning and oriented sample solid-state NMR structural restraints combine for influenza a M2 protein functional insights. J. Am. Chem. Soc. 2012, 134 (22), 9022-5.

(42) Yan, S. H.; Bu, Y. X. Alteration of imidazole dimer on oxidation or water ligation. J. Phys. Chem. B 2004, 108 (36), 13874-13881.

(43) Dong, H.; Yi, M.; Cross, T. A.; Zhou, H. X. Ab initio calculations and validation of the $\mathrm{pH}$-dependent structures of the His37-Trp41 quartet, the heart of acid activation and proton conductance in the M2 protein of Influenza A virus. Chem. Sci. 2013, 4 (7), 2776-2787.

(44) Morris, G. A.; Freeman, R. Enhancement of Nuclear MagneticResonance Signals by Polarization Transfer. J. Am. Chem. Soc. 1979, 101 (3), 760-762.

(45) Oster, C.; Hendriks, K.; Kopec, W.; Chevelkov, V.; Shi, C.; Michl, D.; Lange, S.; Sun, H.; de Groot, B. L.; Lange, A. The conduction pathway of potassium channels is water free under physiological conditions. Sci. Adv. 2019, 5 (7), eaaw6756.

(46) Bennett, A. E.; Ok, J. H.; Griffin, R. G.; Vega, S. Chemical-Shift Correlation Spectroscopy in Rotating Solids - Radio FrequencyDriven Dipolar Recoupling and Longitudinal Exchange. J. Chem. Phys. 1992, 96 (11), 8624-8627.

(47) Hu, J.; Fu, R.; Cross, T. A. The chemical and dynamical influence of the anti-viral drug amantadine on the M2 proton channel transmembrane domain. Biophys. J. 2007, 93 (1), 276-83.

(48) Cady, S. D.; Hong, M. Amantadine-induced conformational and dynamical changes of the influenza M2 transmembrane proton channel. Proc. Natl. Acad. Sci. U. S. A. 2008, 105 (5), 1483-8. 